\title{
LA LEY DOMINICAL, ¿REALIDAD O FALSA EXCITACIÓN?'1
}

\author{
Miguel Ángel SAlomón \\ Docente de LA FacULTAD DE TEOLOGIA - UPEU
}

\section{Introducción}

Toda persona que escucha la predicación de los Adventistas Del Séptimo Día, de alguna manera comienza a tener referencias sobre la futura legislación de las leyes dominicales. Y no puede ser de otra manera, porque el mensaje sobre la observancia del sábado como día de reposo está inserto en el mismo nombre de la denominación adventista, prefijando, de alguna forma, el futuro conflicto en torno a la vigencia del domingo en lugar del sábado. Éste es un asunto que a medida que pasa el tiempo cobra más relevancia. Debido a la nueva configuración del mundo político, social, económico y aun religioso, producido por el surgimiento del nuevo orden mundial y la globalización, el tema de las leyes dominicales adquiere cada vez más vigencia.

Como estudiosos de las profecías, nos damos cuenta de que las leyes dominicales encajan de manera precisa en el contexto en el que vivimos, y declarar su proximidad no significa ninguna exageración o sensacionalismo, según la apreciación de Edward Reid. ${ }^{2}$ Además, la imposición del domingo como día de descanso en lugar del sábado, no será un asunto aislado, sino constituye un elemento focal del gran conflicto milenario y será la última prueba de lealtad que se imponga a la humanidad. Elena de White, hace muchos años declaró: "El sábado será la gran piedra de toque de la lealtad; pues es el punto especialmente controvertido. Cuando esta piedra de toque les sea aplicada finalmente a los

${ }^{1}$ En el artículo anterior se analizó la realidad de la profecía apocalíptica que involucra a los poderes que intervendrán en la gran crisis, según Apocalipsis 13. Ahora se estudiará cómo se está desarrollando esta profecía.

${ }^{2}$ Ver Edward Reid, El domingo viene (Bogotá: Asociación Publicadora Interamericana, 1977), 76. 
hombres, entonces se trazará la línea de demarcación entre los que sirven a Dios y los que no le sirven". ${ }^{3}$

En este artículo nos proponemos en primer lugar mostrar en forma breve las profecías bíblicas referentes a la legislación dominical, apoyadas por Elena de White. En segundo lugar, se pretende mostrar de manera resumida la evolución de las leyes dominicales que se han aprobado en el territorio norteamericano. Finalmente, haremos un análisis de la situación actual sobre los posibles intentos por establecer esta legislación en Norteamérica y cuál debería ser nuestra actitud hacia estos hechos.

\section{Las profecías sobre las leyes dominicales}

Distintos escritores bíblicos, tanto del AT como del NT, señalan la obra que los poderes políticos y religiosos realizarían para intentar cambiar el Decálogo, imponer la observancia del domingo. Veamos algunos: “... pensará en cambiar los tiempos y la ley..." (Dn 7:25); "Y hacía que a todos, pequeños y grandes, ricos y pobres, libres y esclavos, se les pusiese una marca en la mano derecha, o en la frente; y que ninguno pudiese comprar ni vender, sino el que tuviese la marca o el nombre de la bestia o el número de su nombre” (Ap 13:16, 17); “... con la cual han fornicado los reyes de la tierra, y los moradores de la tierra se han embriagado con el vino de su fornicación” (Ap 17:2); "Y la mujer estaba vestida de púrpura y escarlata, y adornada de oro, de piedras preciosas y de perlas, y tenía en la mano un cáliz de oro lleno de abominaciones y de la inmundicia de su fornicación" (Ap 17:4).

En cuanto a la profecía de Daniel, su aplicación corresponde al dominio del Imperio Romano, tanto en su fase política como religiosa. Bajo el dominio del imperio, Constantino fue el primero en dictar una ley que colocó el domingo como un día de descanso, que luego sería aceptado y oficializado por el cristianismo católico. El decreto de Constantino declaraba:

${ }^{3}$ Elena G. de White, El gran conflicto (Buenos Aires: Asociación Casa Editora Sudamericana, 1987), 663 . 
Descansen todos los jueces, la plebe de las ciudades, y los oficios de todas las artes el venerable día del Sol. Pero trabajen libre y lícitamente en las faenas agrícolas los establecidos en los campos, pues acontece con frecuencia, que en ningún otro día se echa el grano a los surcos y se plantan vides en los hoyos más convenientemente, a fin de que en ocasión del momento no se pierda el beneficio concedido por la celestial providencia. ${ }^{4}$

Después de este primer decreto dominical dado en Roma, en los siguientes años, distintos concilios y papas se encargaron de oficializarlo en el seno del catolicismo. De esta manera, el descanso en el día domingo comenzó a reemplazar el reposo sabático. Este proceso lo señala así Frank Yost: 5

El Concilio de Elvira (España), años 305 y 306 d. C.

Concilio de Arlés, año 304 d. C.

Concilio de Nicea 325.

Concilio de Laodicea, 381 y 434.

Concilio de Cartago, 397 d. C.

Concilio de Agde, 506 d. C.

Algunos papas que propiciaron el descanso en el día domingo fueron, entre otros, Melquiades (311-335d. C.); Silvestre (314-335 d.C.); León I (440-461 d. C.).

En este tiempo, los papas han reconocido el hecho que el día domingo tuvo su inicio con el decreto de Constantino. Eso lo hizo, entre uno de ellos, Juan Pablo II, cuando dijo:

Solamente en el siglo IV, la ley civil del Imperio Romano reconoció el ritmo semanal, disponiendo que en el "día del sol" los jueces, las poblaciones de las ciudades y las corporaciones de los diferentes oficios dejaran de trabajar. Los cristianos se alegraron

${ }^{4}$ Frank Herman Yost, Historia del sábado y del domingo-hasta el emperador Constantino (Lima: Editorial Imprenta Unión, 1965), 120.

${ }^{5}$ Ibid., 87-9. 
de ver superados así los obstáculos que hasta entonces habían hecho heroica a veces la observancia del día del Señor. Ellos podían dedicarse ya a la oración en común sin impedimentos. Los Concilios han mantenido, incluso después de la caída del Imperio, las disposiciones relativas al descanso festivo. ${ }^{6}$

En los tiempos posteriores, la justificación que han dado los católicos para el cambio del sábado por el domingo, se encuentra precisamente en el Catecismo Católico que declara al respecto:

La Iglesia, desde la tradición apostólica que tiene su origen en el mismo día de la resurrección de Cristo, celebra el misterio pascual cada ocho días, en el día que se llama con razón "día del Señor' o domingo". El día de la Resurrección de Cristo es a la vez el "primer día de la semana", memorial del primer día de la creación, y el "octavo día" en que Cristo, tras su "reposo" del gran Sabbat, inaugura el Día "que hace el Señor”, el "día que no conoce ocaso" (Liturgia bizantina). El "banquete del Señor" es su centro, porque es aquí donde toda la comunidad de los fieles encuentra al Señor resucitado que los invita a su banquete (cf Jn 21,12; Lc 24, 30). ${ }^{7}$

El mismo papa Juan Pablo II, con su Carta Apostólica Dies Domini, exhorta al mundo cristiano a prestar una cuidadosa observancia del día domingo. Aboga por el apoyo de la ley civil, el cese de espectáculos deportivos y otras actividades seculares en ese día para que los cristianos puedan asistir a las festividades religiosas.

Precisamente, comentando Apocalipsis 13, con referencia al papel de Estados Unidos en torno a su rol con la imposición del día domingo como día de descanso, Elena G. de White declaró:

Se ha demostrado que los Estados Unidos de Norteamérica son representados por la bestia de dos cuernos semejante a los de un

6Juan Pablo II, Carta Apostólica, Dies Domini del 31 de mayo del 1998.

${ }^{7}$ Ver Catecismo Católico (Libreria Editrice Vaticana, 2003). 
cordero, y que esta profecía se cumplirá cuando los Estados Unidos hagan obligatoria la observancia del domingo, que Roma declara ser el signo característico de su supremacía. ${ }^{8}$

Luego, ella identifica no sólo otros actores que participarán de manera directa en relación con la imposición del descanso dominical, sino también otras creencias asociadas con ese cambio.

Merced a los dos errores capitales, el de la inmortalidad del alma y el de la santidad del domingo, Satanás prenderá a los hombres en sus redes. Mientras aquél forma la base del espiritismo, éste crea un lazo de simpatía con Roma. Los protestantes de los Estados Unidos serán los primeros en tender las manos a través de un doble abismo al espiritismo y al poder romano; y bajo la influencia de esta triple alianza ese país marchará en las huellas de Roma, pisoteando los derechos de la conciencia. ${ }^{9}$

\section{El desarrollo de la legislación dominical en los Estados Unidos de América}

Durante el período colonial, varias leyes se dictaron en distintos lugares. La primera ley dominical en Estados Unidos se dictó en Virginia (1610):

Todo hombre y mujer asistirá en la mañana al servicio divino y a los sermones que se predican el día de reposo, y en la tarde al servicio divino, y a la catequesis, bajo pena, por la primera falta, de perder su provisión para la siguiente semana; por la segunda falta, a perder la mencionada provisión, y además ser azotado; y para la tercera falta, la pena de muerte. ${ }^{10}$

${ }^{8}$ Elena G. de White, El gran conflicto (Buenos Aires: Asociación Casa Editora Sudamericana, 1987), 635.

${ }^{9}$ Ibid., 645.

${ }^{10}$ Edward Reid, 99. 
Durante el período de la república, así como esa primera ley, se repitieron otras en fechas sucesivas y en distintos territorios: Massachusetts (1650); Connecticut (1656); Maryland (1692-1715).

El mayor esfuerzo por lograr una ley dominical a nivel nacional fue el proyecto conocido como El proyecto de ley Blair, introducido en el congreso de Norteamérica por el senador H. W. Blair, el 21 de mayo de 1888. Luego de acalorados debates y argumentaciones, finalmente el proyecto no prosperó, debido a la cerrada oposición de judíos, bautistas del séptimo día y adventistas. Reid indica que "Es axiomático que en el escenario de las leyes dominicales del tiempo del fin, los protestantes se unirán a los católicos romanos para implantar una ley dominical en los Estados Unidos". ${ }^{11}$ Es por eso que de manera categórica Elena de White indica: "Los protestantes de Estados Unidos serán los primeros en tender las manos a través de un doble abismo al espiritismo y al poder romano; y bajo la influencia de esta triple alianza ese país marchará en las huellas de Roma, pisoteando los derechos de la conciencia". ${ }^{12}$

Se ve con toda nitidez, a través de la historia, que desde el origen de la primera ley dominical emitida por Constantino, ésta se introdujo casi de inmediato en el ámbito del catolicismo apoyado y reconocido por el clero católico. Posteriormente, la nación Norteamericana siguió en el mismo camino, tratando de imponer el descanso dominical.

\section{Situación actual y las leyes dominicales}

Aceptar la posibilidad que en el país más respetuoso y a la vez defensor de los derechos humanos y de la libertad de conciencia, se dicten leyes contra esos mismos derechos de los ciudadanos parece un contrasentido; sin embargo, dado los antecedentes y las condiciones actuales, todo parece indicar que el tiempo es propicio para que eso suceda.

Debe recordarse que en Norteamérica, tanto en el período colonial como republicano, se han implantado leyes dominicales. Y es más, en el período de la república, entre 1880 y 1890, se indica que en 17 de los 48 estados, se aprobaron estas leyes y debido a esa situación, 76 ad-

${ }^{11}$ Ibid., 105.

${ }^{12}$ Elena G. de White, El gran conflicto, 622. 
ventistas fueron procesados, sentenciados y también perseguidos. ${ }^{13}$

En la actualidad, diferentes personajes, del mundo evangélico y católico de Estados Unidos, se están movilizando para lograr más que un acercamiento entre estos grupos religiosos, lo que finalmente conducirá a lograr la legislación dominical a nivel nacional. Entre ellos se puede citar a Charles Colson, Ralph Reed, Michael Harper, Pat Robertson (autor del Nuevo orden mundial), y otros. El católico Keith Fournier y el evangélico Pat Robertson, firmaron el documento Evangélicos y católicos unidos.

Tanto protestantes y católicos, que abogan por la unidad y el ecumenismo en Norteamérica, indican que esa unión debe basarse en las enseñanzas de Cristo y las creencias fundamentales neotestamentarias, destacando, por sobre todo, el descanso dominical como un elemento integrador de la unión familiar, el rescate de valores y como un freno para el tráfago de la vida materialista.

Más aún, en caso de una eventual aprobación de las leyes dominicales, ellos indican que las minorías afectadas por esta legislación, como los judíos, los adventistas del séptimo día y otros, deberían apoyar el descanso dominical, como el día de descanso común en relación con cualquier otra alternativa o práctica.

Por otra parte, la posición católica en torno a la observancia del domingo no ha cambiado, por el contrario, su posición es cada vez más directa. Por ese motivo, el Catecismo Católico de 1994, lleva el imprimatur de Joseph Ratzinger (hoy Benedicto XVI), considerado en ese tiempo, según la revista Time, "el príncipe más poderoso y uno de los más despreciados de la iglesia", o como "el cardenal más poderoso del mundo...". ${ }^{14}$ Pero lo que más interesa es lo que dice ese catecismo con relación al descanso dominical. En el documento titulado "Cumplimiento dominical del sábado" en el párrafo 2175 , y en especial los números 2187 y 2188, se lee: "La santificación del domingo y los días santos de guardar requieren un esfuerzo común... A pesar de las estrecheces económicas, las autoridades públicas deberían garantizar a los ciudadanos un tiempo especial para dedicarlo al descanso y a la adoración divina. Los empleadores tienen similares obligaciones hacia sus empleados".

${ }^{13}$ Edward Reid, El domingo viene, 97-8.

14“"Keeper of Straigh and Narrow”, Time, 6 de diciembre de 1993. 
Además, se añade, "En aras del respeto a la libertad religiosa y al bien común de todos, los cristianos deberían procurar que se reconozcan el domingo y los días santos de la iglesia como día de descanso obligatorio".

A esto se agrega la presión que ejercen los líderes católicos, hasta con amenazas, a los legisladores de este grupo religioso, para que voten todo proyecto de ley promovido por ellos. En 1995, el papa Juan Pablo II declaró: "Los políticos no pueden renunciar a sus conciencias cuando asumen sus deberes legislativos". ${ }^{15}$

Es necesario estar alertas para comprender lo que está sucediendo en la actualidad. Elena G. de White, con claridad describe lo que verdaderamente está aconteciendo y lo que va a suceder:

Mientras los hombres duermen, Satanás está arreglando activamente los asuntos para que el pueblo de Dios no pueda alcanzar misericordia o justicia. El movimiento dominical está abriéndose paso en las tinieblas. Líderes están ocultando el verdadero asunto, y muchos que se unen con el movimiento no ven hacia dónde se dirige la corriente subterránea. Sus profesiones de fe son suaves y benignas, y aparentemente cristianas; pero cuando hable, revelará el espíritu del dragón. ${ }^{16}$

Vendrá tiempo cuando los hombres no sólo prohibirán que se trabaje en domingo, sino que procurarán mediante la fuerza que se trabaje los sábados. Y se les pedirá que renuncien al sábado y que se adhieran a la observancia del domingo a riesgo de perder su libertad y sus vidas. ${ }^{17}$

\section{Qué deberían hacer los adventistas}

Creo que ningún adventista debe incomodarse, llenarse de temor o asumir alguna actitud contraria a las enseñanzas tanto de la Biblia como

\footnotetext{
${ }^{15}$ National \& International Religion Report, 17 de abril de 1995.

${ }^{16}$ Elena G. de White, The Watchman, párr. 11, 25 diciembre de 1906.

${ }^{17}$ Elena G. de White, The Southern Work, 69.
} 
de Elena de White. Las profecías han sido dadas, en primer lugar, para nuestro conocimiento y, en segundo lugar, para que hagamos la mejor preparación para los tiempos de crisis que se avecinan. Por lo tanto, será muy importante tomar en cuenta cómo deberíamos de reaccionar frente al tiempo en que vivimos. He aquí algunos consejos:

1. Estudiar y conocer las profecías sobre los acontecimientos finales, y estar atentos los acontecimientos que están ocurriendo.

2. Los que están en puestos de responsabilidad deben luchar por mantener el respeto a la libertad de conciencia, en los fueros que sean necesarios.

3. Pasar más tiempo en comunión con Dios.

4. Predicar el Mensaje de los tres ángeles de manera completa, poniendo un énfasis especial en la verdad del "evangelio eterno" y del "sábado".

5. Buscar y reclamar con renovado interés el reavivamiento que permita el derramamiento del Espíritu Santo, mediante las reuniones de familia y en los Grupos Pequeños.

6. Dar testimonio con nuestras vidas en todo momento y circunstancia.

7. Ser conscientes que la persecución vendrá a los que guardan los mandamientos de Dios (Dn 12:1; Mt 24:9-13; Mt 5:11, 12; Ap $2: 10)$. En cada uno de estos textos se aseguran dos cosas. En primer lugar, que la persecución vendrá con toda seguridad sobre cada uno de los hijos fieles de Dios; y en segundo lugar, se hace clara la promesa que Dios protegerá a cada uno de sus hijos y no los abandonará en los momentos más difíciles.

8. Cultivar y aprender un estilo de vida que permita estar preparados para vivir en condiciones extremas, especialmente en los temas de salud y alimentación.

9. Aprender líneas de trabajo u ocupaciones alternativas que permitan liberarnos de la dependencia laboral.

10. Pensar con seriedad sobre la realidad futura de salir de las ciudades y vivir en el campo. Obviamente, esta salida se realizará cuando se dé la ley dominical e inicie la persecución. Hemos recibido el consejo de Elena G. de White en el folleto: De la ciudad al campo.

11. Debemos estar atentos a estas amonestaciones: 
No está lejos el tiempo cuando, como los primeros discípulos, seamos forzados a buscar refugio en los lugares desolados y solitarios. Así como el sitio de Jerusalén por los ejércitos romanos fue una señal para que los cristianos de Judea huyeran, así, cuando el gobierno de nuestra nación (Estados Unidos) promulgue el decreto que imponga el día de descanso papal, será para nosotros una amonestación. Entonces será tiempo de abandonar las grandes ciudades y prepararnos para abandonar las menores en busca de hogares retraídos en lugares apartados entre las montañas. ${ }^{18}$

Que no calle el pueblo que guarda los mandamientos de Dios en este tiempo, como si aceptáramos la situación. La perspectiva que está delante de nosotros es la de librar una guerra continua, a riesgo de prisión, pérdida de la propiedad o la vida misma, para defender la ley de Dios, que está siendo invalidada por las leyes de los hombres. Este texto bíblico se nos citará: "Sométase toda persona a las autoridades superiores [...] Y las que hay, por Dios han sido establecidas. ${ }^{19}$

Ahora, cuando las horas finales de la historia de la humanidad se aproximan raudamente, es el tiempo de buscar a Dios. Es el tiempo de estar preparados y dar nuestro testimonio vibrante acerca de nuestra fe, compartiendo con otros, el mensaje de que Cristo muy pronto vendrá. Nosotros somos sus heraldos.

${ }^{18}$ Elena G. de White, Eventos de los últimos días (Buenos Aires: Asociación Casa Editora Sudamericana, 1994), 124-5.

${ }^{19}$ Elena G. de White, Advent Review and Sabbath Herald, 1 de enero de 1889. 